\title{
Label-free detection of Potassium ion using PEDOT:PSS
}

\author{
June Ho Lee ${ }^{1}$, Hyo Eun Kim¹, Yong-Sang Kim* \\ School of Electronic and Electrical Engineering, Sungkyunkwan University, Seoburo 2066, \\ Jangang gu, Suwon, Gyeonggi 16419, Korea \\ yongsang@skku.edu \\ Yskim651@gmail.com
}

\begin{abstract}
Potassium ion is an important biomarker that plays an important role in heart. Normal potassium levels are between 3.5 and $5.0 \mathrm{mmol} / \mathrm{L}$ Currently, there are method of attaching guanine-rich DNA to the electrode surface or using potentiometry to detect potassium. However, this method of using DNA has disadvantage of being unstable due to DNA. Disadvantage of the potentiometry is a that a chamber must be made for the reference electrode. Therefore, we propose detection mechanism for measuring potassium using PEDOT:PSS property[1]. RGO-PEDOT:PSS was spin-coated at $1200 \mathrm{rpm}$ for $60 \mathrm{~s}$ on ITO glass. ITO spincoated, $\mathrm{Ag} / \mathrm{AgCl}$ electrode, Pt electrode used. The reaction was confirmed by cyclic voltammetry according to the concentration of $\mathrm{KCl}(0.1 \mathrm{mM}-10 \mathrm{mM} \mathrm{KCl})$. As it shows in Fig. 1, in the $C-V$ curve of D.DI water does not occur a peak that indicates redox reaction. On the other hand, the $C-V$ curves of $\mathrm{KCl}$ occur peak voltage about $0.35 \mathrm{~V}$. Their currents increase with higher concentration as shown in Fig. 1.
\end{abstract}

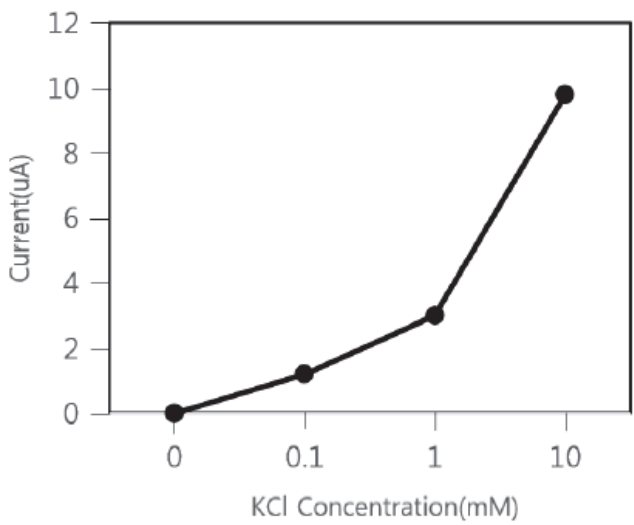

Fig. 1. Current of $\mathrm{KCl}$ using RGO-PEDOT:PSS

Key words: KCI, RGO-PEDOT:PSS , Electrochemical sensor, Cyclic voltammetry

\section{References}

[1] Park, HS, Ko SJ, Park JS, KimJY, Song HK, Scientific reports 3, 2454-2459(2013)

DOI:10.1038/srep02454 